\title{
Does Environmental Regulation Drive away Inbound Foreign Direct Investment? Evidence from a Quasi-Natural Experiment in China
}

\author{
$\mathrm{Yi} \mathrm{Lu}^{\mathrm{a}}$, Mingqin $\mathrm{Wu}^{\mathrm{b}}$, and Linhui $\mathrm{Yu}^{\mathrm{c}}$ \\ ${ }^{a}$ National University of Singapore \\ ${ }^{\mathrm{b}}$ South China Normal University \\ ${ }^{\mathrm{C}}$ Zhejiang University \\ First Draft: May 2012 \\ Revised Version: April 2015
}

\begin{abstract}
This paper investigates whether environmental regulation affects inbound foreign direct investment. Our identification uses the Two Control Zones policy implemented by the Chinese government in 1998. The difference-in-differences and difference-in-difference-in-differences estimations show that cities with tougher environmental regulation attract less foreign direct investment. The negative effect of environmental regulation is stronger for polluting industries than for non-polluting industries.
\end{abstract}

Keywords: Environmental regulation; Foreign direct investment; Pollution haven effect; Difference-in-differences estimation; Difference-in-difference-in-differences estimation; Two control zones

JEL Codes: R11; L25; D22 


\section{Introduction}

Governments across the world, concerned about further deterioration of environments, are toughening their regulations on pollution in the hope that firms will develop greener technologies and produce more environmentally responsible goods. An unintended consequence, however, is that firms may respond by relocating their production to places with less stringent environmental regulations, a phenomenon known as the pollution haven hypothesis. This may not only counteract the effects of environmental policies, but may also worsen the overall scenario. For example, developing countries may manipulate their environmental policies to attract more foreign direct investment (FDI), which could lead to an increase in the overall pollution levels.

Despite much anecdotal evidence, however, empirical studies fail to provide conclusive results on the effect of environmental regulation, with some finding no such effect ${ }^{1}$ and others documenting significant effects. ${ }^{2}$ As a result, the investigation of the pollution haven hypothesis is considered to be "one of the most contentious issues in the debate regarding international trade, foreign investment, and the environment" (Kellenberg, 2009).

An inherent empirical challenge to identify an effect of environmental regulation on firms' location choice is how to deal with the potential endogeneity of environmental regulation. $^{3}$ Much of the existing literature treats environmental regulations as exogenous (see Levinson, 2008 for a survey). Recent studies have started to tackle the potential endogeneity of environmental regulations, by for example using either the instrumental variable approach (see Millimet and Roy, 2011, for a survey) or the difference-in-differences semi-non-parametric propensity score matching method (List, Millimet, Fredriksson, and McHone, 2003; List, McHone, and Millimet, 2004; Millimet and List, 2004).

We examine whether environmental regulation affects inbound FDI by using a change in environmental policy in China, the implementation of the Two Control Zones (TCZ) policy (for details about environmental regulations in China, see Section 2). Specifically, we explore two variations, time (before and after the policy change) and cross-sectional (the new environmental policy applied in some cities - the treatment group, but not in others - the control group), to conduct a difference-in-differences (DID) analysis. Our DID estimation shows that cities with tougher environmental regulations attract less FDI, which confirms the pollution haven hypothesis. Meanwhile, the magnitude of the

\footnotetext{
${ }^{1}$ For example, Friedman, Gerlowski, and Silberman (1992); Levinson (1996); Eskeland and Harrison (2003); Javorcik and Wei (2004). In a related study, List (1999) show that air pollution emissions in the U.S. converged during the 1929-1994 period, suggesting that states in the U.S. did not compete for industries by loosening their environmental regulations.

${ }^{2}$ For example, Henderson (1996); Becker and Henderson (2000); List and Co (2000); Keller and Levinson (2002); List, Millimet, Fredriksson, and McHone (2003); Kellenberg (2009).

${ }^{3}$ Jeppesen, List, and Folmer (2002) conduct a meta-analysis and conclude that differences in methodological considerations explain much of the variation in the findings about the effect of environmental regulation.
} 
regulatory effect is found to be large but comparable with those in the literature (e.g., Becker and Henderson, 2000; Kellenberg, 2009): toughening environmental regulations causes the amount of FDI to drop by around $33.3 \%$.

The validity of our DID estimation hinges on the condition that cities in the treatment group would have followed the trend of the control group in attracting FDI if they had not implemented the new environmental policy. To verify whether this identifying assumption is satisfied, we conduct a series of sensitivity analyses. First, we control for the trend in post-treatment FDI generated by the determinants of the TCZ designation. We then experiment with saturating the model with a city-specific time trend, checking any expectation effect, controlling for other policy reforms taking place at around the same time, and conducting two placebo tests. Our findings on the negative effect of environmental regulation on FDI remain robust to all of these validity checks.

While the aforementioned estimations calculate the average effect of environmental regulation over all industries, the effect could vary across industries, especially between polluting and non-polluting industries. By using another data source allowing the calculation of FDI at the city-industry-year level, we find that the effect of environmental regulation on FDI is negative and is statistically significant for polluting industries, but is statistically insignificant for non-polluting industries. Furthermore, the city-industry-year level data enables us to conduct a difference-in-difference-in-differences (DDD) analysis, which improves on the aforementioned DID estimations by including a whole set of cityyear fixed effects, city-industry fixed effects, and industry-year fixed effects. Our triple difference estimation reinforces the DID estimation results, that is, environmental regulation has a negative and statistically significant effect on inbound FDI.

In addition to changes in its environmental policies, China provides an ideal setting for investigating the pollution haven hypothesis. On the one hand, Chinese governments have been attracting FDI aggressively since 1978 when China adopted its opening up and reforming policy, and this has made China the second-largest FDI (stock) recipient country in the world. ${ }^{4}$ On the other hand, China's fast economic growth in recent decades has been accompanied by severe environmental degeneration, including over-exploitation and mass industrial pollution, which are typical problems in developing countries. China is also a large country with substantial differences in the distribution of FDI and in environmental quality, which provides us with enough variations to identify the effect of environmental regulation.

Our study is similar to and complements other studies using a change in environmental regulations, specifically, the Clean Air Act and its amendment in the U.S. For example, Becker and Henderson (2000) use panel data for the period from 1963 to 1992 and find that the birth rate for firms in polluting industries in non-attainment areas (places that have tougher regulations) is reduced by $26-45 \%$. Recently, Hanna (2011)

\footnotetext{
${ }^{4}$ Based on statistics from the CIA World Factbook (accessed on August 15, 2013).
} 
uses a DID analysis to investigate how the Clean Air Act Amendments in the U.S. have affected its outflow FDI, and Chung (2014) uses the same approach to study how the change in environmental laxity in foreign countries affects foreign investment by Korean multinationals. Whereas these studies look at the developed countries, we use data from China, the largest developing country in the world. Moreover, we investigate whether environmental regulation affects inbound FDI, whereas Hanna (2011) and Chung (2014) examines the behavior of outbound FDI.

In the context of China, Dean, Lovely, and Wang (2009), using a sample of equity joint venture (EJV) projects, find that levies on water pollution only affect location choice by EJVs in highly-polluting industries and from Hong Kong, Macao, and Taiwan. Our study differs from theirs by using a different identification strategy (i.e., DID versus a discrete choice model), an investigation of a different environmental regulation (i.e., air versus water pollution), and a different sample period (i.e., 1992-2009 versus 1993-1996). Meanwhile, Hering and Poncet (2014) also explore the change in pollution regulations to investigate how environmental regulations affect firms' exporting activities.

The remainder of this paper is organized as follows. The institutional background of environmental regulations in China, data and variables, and estimation specification are described in Section 2. Empirical findings are presented in Section 3. The paper concludes with Section 4.

\section{Estimation Strategy}

\subsection{Environmental Regulations in China}

Timeline.-SO2 emissions generated by coal combustion have substantially increased alongside the fast economic growth in China in recent decades. National coal consumption in 1990 was 1.05 billion tons, and it increased to 1.28 billion tons in 1995. In 1993, 62.3\% of cities in China had annual average ambient SO2 concentration values above the national Class II standard. In Chongqing, the annual ambient SO2 concentration reached 270 or 4.5 times the national Class II standard. Around the same period, $40 \%$ of the national territory reported acid rain with an average $\mathrm{pH}$ value of less than 5.6.

SO2 and acid rain may harm human health and destroy ecosystems, and may consequently impede economic growth. Chinese governments were concerned with China's long-term sustainable economic development, and started to tackle air pollution issues in the mid-1980s by implementing a series of regulatory policies. The Air Pollution Prevention and Control Law of the People's Republic of China (APPCL) was enacted in 1987 and came into force in 1988. This new environmental law contained general principles of air pollution regulation for local governments and related agencies. However, the APPCL was sketchy. For example, it did not present any concrete policies on how to control SO2 
emissions, nor did it specify which government body should be responsible for enforcing the policies. As a result, the effect of the regulation on air pollution was limited, with SO2 emissions and acid rain continuing to increase in the late 1980s and early 1990s.

With the growing concern about the air pollution problem, the Chinese government decided to take stricter measures. In 1995, the 1987 APPCL was amended, and a section about the regulation of air pollution and SO2 emissions was included. More importantly, a new policy, namely the Two Control Zones (TCZ) policy, was proposed to prevent the air quality of heavily-polluted areas from deteriorating further.

In 1997, "The Request for Approval of the Proposal of Designation for Acid Rain Control Areas and SO2 Pollution Control Areas" was issued by the National Environmental Protection Bureau (NEPB) and sent to the State Council (or the cabinet) for approval. In January 1998, the proposal was approved by the State Council in its document "The Official Reply of the State Council Concerning Acid Rain Control Areas and SO2 Pollution Control Areas". The proposal was then put into effect. From a total of 380 prefecture-cities, 175 cities, accounting for $11.4 \%$ of the nation's territory, $40.6 \%$ of population, $62.4 \%$ of GDP, and $58.9 \%$ of total SO2 emissions in 1995, were designated as TCZ cities (Hao, Wang, Liu, and He, 2001). Figure 1 shows the geographic distribution of TCZ cities in China. In general, SO2 pollution control zones are located in northern China because of the reliance there on thermal energy for heating, whereas acid rain control zones are located in southern China where the climate is relatively more humid.

\section{[Insert Figure 1 Here]}

Criteria.-The two control zones comprise SO2 pollution control zones and acid rain control zones. The NEPB began designating cities as TCZ cities in late 1995, using several criteria. Specifically, a city was designated as an SO2 pollution control zone if: (1) its average annual ambient SO2 concentration had been larger than the national Class II standard (i.e., $60 \mathrm{ug} / \mathrm{m} 3$ ) in recent years; (2) its daily average ambient SO2 concentrations exceeded the national Class III standard (i.e., $250 \mathrm{ug} / \mathrm{m} 3$ ); or (3) its SO2 emissions were significant. And a city was designated as an acid rain control zone if: (1) the average $\mathrm{pH}$ value of its precipitation was equal to or less than 4.5; (2) its sulfate deposition was above the critical load; or (3) its SO2 emissions were large.

New Policies. - Once a city was designated as a TCZ city, tougher regulatory policies were implemented. For example:

1. New collieries based on coal with a sulfur content of $3 \%$ and above were prohibited, and existing collieries using a similar quality of coal had to gradually reduce the production or be shut down;

2. New coal-burning thermal power plants were prohibited in city propers and in 
suburbs of larger or medium cities, except for cogeneration plants whose primary purpose was to supply heat. Furthermore, newly constructed or renovated coalburning thermal power plants using coal with a sulfur content of $1.5 \%$ and above had to install sulfur-scrubbers, while existing power plants using similar quality of coal had to adopt SO2 emission-reduction measures by 2000;

3. In polluting industries such as the chemical engineering, metallurgy, nonferrous metals and building materials industries, production technologies and equipment generating severe air pollution had to be phased out;

4. Local governments had to strengthen the collection, administration and use of SO2 emission fees.

Enforcement. - In the 1998 reply, the State Council also laid out the targets for environmental controls in the TCZ cities in the short run (by 2000) and in the long run (by 2010). Specifically, by the end of 2000, "the sources of industrial SO2 pollution should achieve the national standard of SO2 emission. The total amount of SO2 emission should be within the required amount. Ambient SO2 concentrations in important cities should achieve the national standards. The acid rain in the acid rain control zones should be alleviated." By the end of 2010, "the total amount of SO2 emission should be lower than that in 2000. Ambient SO2 concentrations in all cities should achieve the national standards. The number of acid rain areas with average $\mathrm{pH}$ value of precipitation equal to or less than 4.5 should be reduced significantly."

These new environmental regulations have generated a significant improvement in air pollution control. In 2000, 102 TCZ cities achieved the national Class II standard for average ambient SO2 concentrations and $84.3 \%$ of severely-polluting firms achieved the target level for SO2 emissions (China Environment Yearbook, 2001). The average growth rate in SO2 emissions from industries and domestic activities in TCZ cities from 2001 to 2006 was $-6.5 \%$ (Annual Statistic Report on Environment in China, 2007). In 2010, $94.9 \%$ of TCZ cities had achieved the national Class II standard for average ambient SO2 concentrations, with no city reporting values above the national Class III standard (Report of Ministry of Environmental Protection of the People's Republic of China, 2011). For more discussion on the effectiveness of the TCZ policies, see He, Huo, and Zhang (2002), Yang, Cao, Ge, and Gao (2002), etc.

\subsection{Data and Variables}

Our analysis draws on data from the following three sources:

1. The Chinese City Statistical Yearbook for the period 1992 (the earliest) to 2009 (the most recent) 
2. The State Council's official document, "The Official Reply of the State Council Concerning Acid Rain Control Areas and SO2 Pollution Control Areas"

3. A survey of foreign-invested enterprises in 2001

From the first data source, we collect yearly data about our outcome variable, the amount of (realized) FDI for each city during the 1992-2009 period, as well as other city characteristics.

From the second data source, we obtain a detailed list of the names of the cities designated as TCZ cities. During our sample period (1992-2009), the composition of this list remained unchanged. Appendix Table A1 contains this list. Of the total of 280 cities for which the Chinese City Statistical Yearbook has information, 158 are TCZ cities.

One shortcoming of the Chinese City Statistical Yearbook is that it does not have information about FDI for different industries or sectors, which forces us to estimate the average effect of environmental regulation across all industries, and prohibits the examination of differential effects for polluting and non-polluting industries. To overcome this drawback, we supplement our main analysis, based on the Chinese City Statistical Yearbook, with the fourth data source. Specifically, the survey of foreign-invested enterprises contains information about the date of establishment, the registered capital, the industrial affiliation and the location of around 150,000 foreign-invested enterprises in 2001 (or approximately $75 \%$ of all foreign-invested enterprises).

\subsection{Specification}

To identify the effect of environmental regulation on FDI, we exploit the TCZ policy that was put into effect in China in 1998 as a quasi-natural experiment, and conduct a DID analysis. Specifically, there are two groups of cities, the treatment group comprising cities designated as TCZ cities in 1998, and the control group comprising non-TCZ cities. We compare the total amount of FDI in TCZ cities before and after the adoption of the TCZ policy in 1998 with the corresponding change in non-TCZ cities during the same period.

The DID estimation specification is as follows:

$$
Y_{c t}=\alpha_{c}+\gamma \cdot T C Z_{c} \times \text { Post }_{t}+\delta_{t}+\mathbf{X}_{c t}^{\prime} \boldsymbol{\beta}+\varepsilon_{c t},
$$

where $Y_{c t}$ is the logarithm of FDI in city $c$ at year $t$; $T C Z_{c}$ indicates city $c$ 's TCZ status in 1998, i.e., $T C Z_{c}=1$ if city $c$ is a TCZ city; and $=0$ if city $c$ is a non-TCZ city; Post indicates the post-treatment period, i.e., Post $_{c}=1 \forall t \geq 1998$ and $=0$ otherwise; and $\varepsilon_{c t}$ is the error term. To deal with potential heteroskedasticity and serial correlation, we cluster the standard errors at the city level, following Bertrand, Duflo, and Mullainathan (2004). 
$\mathbf{X}_{c t}$ is a vector of many other potential determinants of FDI that are included to isolate the effect of environmental policy. These controls include agglomeration economies (i.e., domestic output), ${ }^{5}$ market size (i.e., retail consumption), economic growth, education (i.e., number of college students and number of high school students), and infrastructure (i.e., electricity consumption, number of telephones, and road area). See Table 1 for the detailed construction and summary statistics of these variables.

\section{[Insert Table 1 Here]}

$\alpha_{c}$ is the city dummy, capturing city c's all time-invariant characteristics such as geographic features, climate, natural endowment, etc; and $\delta_{t}$ is the time dummy, capturing all yearly factors common to all cities such as business cycle, monetary policy, macro shocks, etc. As Chinese provinces usually have different regional policies and guidelines for policy enforcement, we further replace year dummies with province-year dummies $\left(\delta_{p t}\right)$ to control for any arbitrary (time-varying or time-invariant) provincial compounding factors. The inclusion of province-year dummies also provides us with a control for the spatial correlation issues pointed out by Drukker and Millimet (2008). ${ }^{6}$

The identifying assumption associated with the DID estimation specification (1) is that conditional on a whole list of controls $\left(\alpha_{c}, \delta_{p t}, \mathbf{X}_{c t}\right)$, our regressor of interest, $T C Z_{c} \times$ Post $_{t}$, is uncorrelated with the error term, $\varepsilon_{c t}$, i.e., ${ }^{7}$

$$
E\left[\varepsilon_{c t} \mid T C Z_{c} \times \text { Post }_{t}, \alpha_{c}, \delta_{p t}, \mathbf{X}_{c t}\right]=E\left[\varepsilon_{c t} \mid \alpha_{c}, \delta_{p t}, \mathbf{X}_{c t}\right] .
$$

As further checks on this identifying assumption, we provide a battery of sensitivity analyses, including controlling for city-specific linear time trend, a check on the expectation effect, controlling for the flexible effects caused by the determinants of the TCZ designation, controlling for three other events (the on-going Asian financial crisis, stateowned-enterprises (SOEs) reform, and the relaxation of FDI regulations) that happened at around the same time as the TCZ policy, two placebo tests with the random assignment of TCZ reform, and a triple difference estimation. For details, see sections 3.2-3.3.

\footnotetext{
${ }^{5}$ An alternative way of capturing agglomeration economies in the literature is to include the historical stock of FDI (e.g., Wagner and Timmins, 2009). In column 1 of Appendix Table A2, we experiment with this alternative measure of the agglomeration effect, and find robust results.

${ }^{6}$ As an alternative check, we follow the literature in including a spatially lagged FDI measure (i.e., the inverse-distance-weighted average of the FDI received by all other cities) as an additional control variable in the regression. As shown in column 2 of Appendix Table A2, our results remain robust to this additional control.

${ }^{7}$ Note that the identification does not require our control variables to be exogeneous, i.e.,

$$
E\left[\varepsilon_{c t} \mid \alpha_{c}, \delta_{p t}, \mathbf{X}_{c t}\right]=0 .
$$

In other words, the estimated coefficients for these control variables may not have a causal interpretation. See Stock and Watson (2012, p274) for more discussion on this point and the proof.
} 


\section{Empirical Findings}

\subsection{Main Results}

Graphical Results. - One virtue of the DID analysis is that it can use figures to give a transparent demonstration of how the pollution regulation effect is identified. To this end, we start with presenting the time trends of FDI flows in TCZ and non-TCZ cities as well as their differences in Figures 2. The difference in the amount of FDI between TCZ and non-TCZ cities continued to grow during the pre-treatment period (i.e., 1992-1997), but started to narrow immediately after the implementation of the pollution regulation in 1998. These results imply that tougher environmental regulations (i.e., the implementation of the TCZ policy) drive away inbound FDI, supporting the pollution haven hypothesis.

\section{[Insert Figure 2 Here]}

Regression Results. - The baseline estimation results are presented in Table 2. In column 1, we include city and year fixed effects and other time varying city characteristics $\mathbf{X}_{c t}$. In column 2, we further replace year fixed effects with province-year fixed effects, and hence, the identification comes from the comparison between TCZ and non-TCZ cities within the same province. The interaction between the indicator of the treatment status $T C Z_{c}$ and that of the post-treatment period Post $t_{t}$ is negative and statistically significant. This result implies that cities with tougher environmental regulations (i.e., where the TCZ policy has been implemented) attracted less FDI, further confirming the pollution haven hypothesis.

\section{[Insert Table 1 Here]}

One could be concerned that the designation of TCZ cities in 1997 was not randomly determined, and hence, TCZ and non-TCZ cities could be systematically different before the treatment, which may spuriously generate the negative effect of environmental regulations on FDI. To address this concern, we augment our DID estimation following Gentzknow (2006). Specifically, in the Appendix, we first identify what are significant determinants of the TCZ designation in 1997. As shown in Appendix Table A3, three sets of determinants are important: 1) geographic locations - cities in northern and coastal areas were less likely to be chosen as TCZ cities; 2) city levels - municipality or provincial capital city and special economic zones were more likely to become TCZ cities; ${ }^{8} 3$ ) industry structure old industrial cities and cities with more industry production and more SO2-polluting industries were more likely to be selected as TCZ cities. Meanwhile, condi-

\footnotetext{
${ }^{8}$ Municipalities (Beijing, Chongqing, Shanghai, and Tianjin) are higher in the political hierarchy level than other cities. To show that our results are not biased to the political structure of cities, we, in column 3 of Appendix Table A2, experiment with the exclusion of these municipalities, and find similar results.
} 
tional on these determinants, we do not find evidence of the TCZ status being determined by past FDI, thereby relieving the concern about reverse causality.

We then add interactions between these significant determinants of the TCZ designation and the post-treatment period indicator $\left(\right.$ Post $\left._{t}\right)$ to control for flexible time trends in FDI generated by these determinants in column 3. Consistently, we find that environmental regulation has a negative and statistically significant effect on the amount of FDI.

Interpretation. - There are two possible reasons why tough environmental regulations drive away FDI in China. First, the TCZ policies require that outdated, dirty production technologies and equipment are phased out, and they strengthen the collection of SO2 emission fees, which increases production costs particularly for polluting industries in the TCZ cities. Second, the TCZ policies also prohibit the establishment of new collieries and new coal-burning thermal power plants that use low quality of coal, and they require the installation of desulfurization equipment in existing power plants, which leads to an increase in electricity costs faced by firms in the TCZ cities because coal is still the main fuel source for power in China.

Ideally, we can test the differential effects of environmental regulation on FDI for polluting industries and non-polluting industries, with the former being stronger and the latter being smaller and potentially even insignificant. However, the city-level data used in the main analysis does not have information about inward FDI disaggregated at the sector level; hence, our estimation of $\gamma$ reflects the average effect of environmental regulation (over industries with different degrees of pollution). Later, we supplement our city-level data with data of foreign-invested enterprises in 2001, which allows us to check whether the effect of environmental regulation on FDI is different across different industries.

Economic Magnitude. - The economic magnitude of the effect of environmental regulation is found to be significant. Using the estimate in column 3 , we find that the implementation of the TCZ policy caused the amount of FDI to drop by 33.3\%. This magnitude is comparable to those found in the literature. ${ }^{9}$ For example, Becker and Henderson (2000) find that tougher environment regulations caused the birth rate of firms in polluting industries to drop by $26-45 \%$ in the U.S.. Kellenberg (2009) estimates that during 1999-2003, a failing environmental policy caused the value added of U.S. affiliates located in the top 20th percentile of countries to grow by approximately $8.6 \%$, while the corresponding number for the top 20th percentile of developing and transition economies was 32\%. Hanna (2011) finds that the Clean Air Act Amendments in the U.S. between 1966 and 1999 increased U.S. multinationals' foreign assets by $5.3 \%$ and foreign output

\footnotetext{
${ }^{9}$ Note that these studies are conducted using different methods and different data, and at different time; hence, the magnitude comparison should be interpreted with caution.
} 
by $9 \%$. Using the data on foreign investment by Korean multinationals, Chung (2014) finds that when a foreign country increases its environmental laxity relative to Korea by one standard deviation from the mean, there is an $12.4 \%$ increase in investment by Korean multinationals from an industry one standard deviation above the mean pollution intensity than an industry at the mean pollution intensity.

Investment Deflection. - From a policy viewpoint, it is interesting to know whether the negative effect of environmental regulation is due to the withdrawal of FDI from China or the deflection of FDI from TCZ to non-TCZ cities. If the latter channel plays a significant role, then the effect found in the aforementioned analysis could be exaggerated. While it is difficult to distinguish between these two channels, we provide two additional tests to shed light on the extent of investment deflection, based on the premise that investment deflection is relatively easier among neighboring places. First, when we replace the year fixed effects with the province-year fixed effects, the comparison moves from being between any TCZ and non-TCZ cities to being between TCZ and non-TCZ cities located in the same province. Hence, if there were a deflection effect, we should find a much smaller effect of environmental regulation in the regression with the year fixed effects than in the one with the province-year fixed effects. Clearly, we obtain the opposite effect, i.e., the coefficient drop from -0.318 in the regression with year fixed effect to -0.276 in the regression with province-year fixed effect.

Second, for each TCZ city, we construct an alternative control group comprised of all its neighboring non-TCZ cities. Specifically, if a TCZ city and a non-TCZ city share a border, then the non-TCZ city is defined as a neighboring city of the TCZ city. If there were a deflection effect, we should detect a larger effect of environmental regulation using this alternative control group. ${ }^{10}$ However, as shown in Column 4 of Table 2, the estimated coefficient from the regression using this alternative control group is almost identical to the one obtained before.

These two exercises together suggest that the tougher environmental regulation may cause foreign multinationals to seek other places in the world to invest.

\subsection{Robustness Checks}

In this sub-section, we conduct a battery of further robustness checks on our aforementioned results.

City-specific Linear Time Trend.-While we have controlled for the post-treatment FDI trend generated by those significant determinants of TCZ designation, one may still be concerned about some other unidentified (or unobserved) characteristics that may

\footnotetext{
${ }^{10}$ Note that the number of observations increases due to the fact that a non-TCZ city may be used multiple times in constructing control groups for different TCZ cities.
} 
generate both the TCZ status and differential trajectories of ex post FDI between TCZ and non-TCZ cities. As a robustness check, we saturate our DID estimation specification with the inclusion of a city-specific linear time trend, which effectively controls for the FDI time trend generated by all city characteristics in a restricted way (i.e., a linear time trend). The regression results are reported in column 1 of Table 3 . It is found that the effect of environmental regulation on FDI remains statistically significant.

\section{[Insert Table 3 Here]}

Expectation Effect.-Another potential concern regards the timing of the change in environmental policy. Specifically, as the NEPB began compiling the TCZ list in late 1995 and took two years to get approval from the State Council, one may be concerned about whether there is any expectation effect, that is, whether the effect of environmental regulation on FDI happened before the effective date of the policy (i.e., 1998). To address this concern, we conduct two robustness checks. First, we include in the regression, an additional control, indicating the implementation of TCZ policies in the following year. If there were an expectation effect, we should find the comparison between TCZ and nonTCZ cities to be significantly different before the adoption of the TCZ policies. Clearly, we find no significant effect of adopting the TCZ policies in the following year in column 2 of Table 3, and our main results barely change.

Second, we conduct a placebo test by using 1996 as the time of treatment instead of the real effective date of 1998. If there is no expectation effect and the treatment and control groups are comparable before the treatment, then the estimation using 1996 as the time of treatment should not show any statistical significance. Indeed, we find that it is statistically insignificant (column 3 of Table 3 ).

Other Policy Shocks. - If other policies were adopted at the same time, any findings about the treatment effect cannot be attributed only to the effect of environmental regulation. There are three important events that happened at around the same time as the TCZ reform: the on-going Asian financial crisis, the SOE reform, and the relaxation of the FDI regulations (which allowed more wholly-owned FDI instead of equity joint ventures). If the Asian financial crisis hit TCZ cities more strongly, if SOE reform was carried out more widely in TCZ cities than in non-TCZ cities, or if equity joint ventures were more concentrated in TCZ cities, our aforementioned estimates of the effect of environmental regulation could be contaminated. To address this concern, we construct

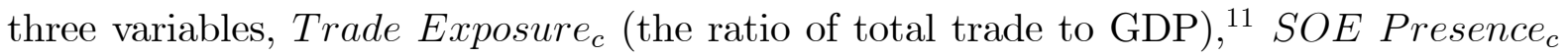
(the percentage of SOEs among all firms), and WFDI Presence $_{c}$ (the percentage of wholly-owned FDI among all foreign-invested firms), all measured as an average during

\footnotetext{
${ }^{11}$ Unfortunately, there is no information regarding the trade exposure to Asian countries like Tailand that were affected by the financial crisis. Hence, we resort to the general level of trade exposure.
} 
the pre-treatment period, to capture potential impacts of the Asian financial crisis, SOEs reform and FDI policy reform across cities, respectively. We then interact these three variables with the indicator of the post-treatment period $\left(\right.$ Post $\left._{t}\right)$ and include the three

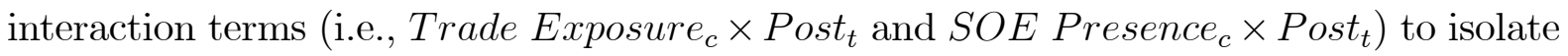
the effect of environmental regulation. The regression results are reported in columns 4-6 of Table 3. Clearly, none of these three interaction terms has any statistical power. More importantly, our estimated effect of environmental regulation remains nearly unchanged in terms of both statistical significance and economic magnitude.

Placebo Tests. - Here, we take a closer look at the identification issues. Specifically, let $\varepsilon_{c t}=\beta \omega_{c t}+\tilde{\varepsilon}_{c t}$, such that $\operatorname{cov}\left(T C Z_{c} \times\right.$ Post $\left._{t}, \omega_{c t} \mid \mathbf{W}_{c t}\right) \neq 0$ and $\operatorname{cov}\left(T C Z_{c} \times\right.$ Post $\left._{t}, \tilde{\varepsilon}_{c t} \mid \mathbf{W}_{c t}\right)=\mathbf{I}$ 0 , where $\mathbf{W}_{c t}$ summarizes all the controls in the regressions. In other words, all the identification issues come from $\omega_{c t}{ }^{12}$ Hence, our estimator $\hat{\gamma}$ is

$$
\hat{\gamma}=\gamma+\beta \delta
$$

where $\delta \equiv \frac{\operatorname{cov}\left(T C Z_{c} \times \text { Post }_{t}, \omega_{c t} \mid \mathbf{W}_{c t}\right)}{\operatorname{var}\left(T C Z_{c} \times \text { Post }_{t} \mid \mathbf{W}_{c t}\right)}$. And $\hat{\gamma} \neq \gamma$ if $\beta \delta \neq 0$.

To further check whether our results are biased due to the omitted variable $\omega_{c t}$, we conduct two placebo tests. First, we construct an artificial treatment group only comprising some non-TCZ cities and compare them to the remaining non-TCZ cities (see, for example, Belot and James, 2011). Given that no TCZ policies were actually implemented in any of non-TCZ cities, the comparison should not generate significant difference. Specifically, we use all non-TCZ cities that are adjacent to one or more TCZ cities (i.e., that share borders) to construct our artificial treatment group, and those nonTCZ cities that are not adjacent to any TCZ cities are regarded as the control group. The regression results are reported in Column 7 of Table 3. As expected, the estimated coefficient of $T C Z_{c} \times$ Post $_{t}$ is not only statistically insignificant (and is even positive).

Second, we randomly assign the TCZ status to cities and the timing of the implementation of TCZ policies. Specifically, in our regression sample, there are 158 TCZ cities of 280 cities, and the TCZ policies were adopted in 1998. We first randomly select 158 cities from the total 280 cities and assign them as TCZ cities; then, we randomly choose a year from 1993-2008 (to make sure we have at least one year before the treatment and one year after the treatment for our DID analysis) as the implementation year of TCZ policies; finally, we construct a false TCZ reform variable from these two randomization, i.e., $T C Z_{c}^{\text {false }} \times$ Post $_{t}^{\text {false }}$. The randomization ensures that $T C Z_{c}^{\text {false }} \times$ Post $_{t}^{\text {false }}$ should have no effect on FDI inflow (i.e., $\gamma^{\text {false }}=0$ ); hence, if $\beta=0$, we have $\hat{\gamma}^{\text {false }}=0$. We

\footnotetext{
${ }^{12}$ One example of the potential remaining omitted variables is the dynamic expansion considerations by foreign multinationals in China. Specifically, foreign multinationals may set up their affiliates in the coastal regions (where more TCZ cities are located) and gradually expand into inland regions (where non-TCZ cities are concentrated). And if these expansion decisions coincided with the adoption of TCZ policies in 1998, our estimation results then do not reflect the effect of environmental regulations.
} 
conduct this random data generating process 500 times to avoid contamination by any rare events (e.g., $\gamma^{\text {false }} \neq 0$ ). Figure 3 shows the distribution of estimates from the 500 times of randomization and our estimate from column 3 of Table 2 . We find that the distribution of estimates from random assignments is centered around zero (the mean value is -0.002 ), and the standard deviation of the estimates is 0.087 , suggesting that $\hat{\gamma}^{\text {false }}=0$. In addition, our estimate clearly lies outside the estimates from the placebo tests, suggesting that it is not caused by omitted variables.

\section{[Insert Figure 3 Here]}

\subsection{Heterogenous Effects and Triple-Difference Estimation}

As discussed in section 3.1, the effect of environmental regulation on FDI could be stronger for polluting industries than for non-polluting industries. To check this differential effect, we use the survey of foreign-invested enterprises in 2001. Specifically, we aggregate the amount of FDI (regardless of whether the firm is an equity joint venture, a contractual joint venture or a wholly-owned foreign-invested firm) from firm-level to city-level. However, the aggregation requires firms' location information at the time of establishment, but we only have access to the survey of foreign-invested enterprises in 2001. As a result, we need to extrapolate firms' location information at the time of entry during the 1992-2000 period. To this end, we use firms' current locations as their locations of establishment, by assuming there is no change to the location of any firm since it was established and ignoring the exits. Meanwhile, based on the SO2 emission data for 19952004, we classify industries with an average SO2 emission of more than 300,000 tons as polluting industries, and the remaining as non-polluting industries (for a similar practice, see Keller and Levinson, 2002; Dean and Lovely, 2010). ${ }^{13}$

The regression results for these two sub-samples are reported in columns 1-2 of Table 4. Interestingly, we find that the effect of environmental regulation on FDI is negative and statistically significant for polluting industries, but is statistically insignificant for non-polluting industries, consistent with our argument.

\section{[Insert Table 4 Here]}

With a breakdown of FDI at the city-industry-year level, we are able to further improve our aforementioned DID estimation by conducting a DDD estimation. Specifically,

\footnotetext{
${ }^{13}$ Polluting industries include Firepower Electricity, Production and Distribution of Heat Power, Smelting and Pressing of Non-Ferrous Metals, Smelting and Processing of Ferrous Metals, Manufacture of NonMetallic Mineral Products, Manufacture of Raw Chemical Materials and Chemical Products, Processing of Petroleum, Coking and Nuclear Fuel, and Manufacture of Paper and Paper Products.
} 
the DDD estimation specification is

$$
Y_{i c t}=\gamma \cdot T C Z_{c} \times \text { Post }_{t} \times \text { Polluting }_{i}+\eta_{c t}+\lambda_{i c}+\varphi_{i t}+\varepsilon_{i c t}
$$

where Polluting Pis $_{i}$ an indicator of polluting industries. The triple-difference estimation allows us to control a whole set of industry-year fixed effects, industry-city fixed effects and city-year fixed effects. In other words, all time-varying and time-invariant city characteristics have been controlled for, and so have time-varying and time-invariant industry characteristics and city-industry characteristics. ${ }^{14}$

The regression results are reported in column 3 of Table 4 . It is found that the triple interaction term has a negative and statistically significant effect, implying that environmental regulation causes the FDI to drop more in polluting industries. These results reinforce our aforementioned DID estimation results on the negative effect of environmental regulation on FDI.

\section{Conclusion}

In this paper, we investigate whether firms respond to environmental regulations by reallocating their production to places with less stringent regulations. To control for the potential endogeneity of environmental regulations, we use a change in environmental policy, namely China's 1998 TCZ policy. Our identification of the effect of environmental regulation comes from a comparison of the outcome variable for TCZ cities with that for non-TCZ cities before and after the policy change, or the DID estimation.

By using the amount of FDI for 280 cities over the 1992-2009 period, we find that cities designated as TCZ attract around 33.3\% less FDI than their non-TCZ counterparts. The results are robust to a series of robustness checks on the identifying assumption, and to checks on other econometric concerns. Moreover, we find that environmental regulation significantly drives away FDI in polluting industries but barely affects FDI in non-polluting industries.

Our paper contributes to the literature on the pollution haven hypothesis by carefully addressing the endogeneity problem associated with environmental regulations. Meanwhile, our use of data from a developing country complements existing studies that focus more on developed countries, particularly the U.S.

\footnotetext{
${ }^{14} \mathrm{~A}$ drawback in this triple difference estimation is that the effect of TCZ status on FDI in non-polluting industries may not be zero, and hence the TCZ effect may be underestimated.
} 


\section{References}

[1] Becker, Randy and Vernon Henderson. 2000. "Effects of Air Quality Regulations on Polluting Industries", Journal of Political Economy 108, 379-421

[2] Belot, Michèle and Jonathan Jamesb. 2011. "Healthy School Meals and Educational Outcomes", Journal of Health Economics 30, 489-504

[3] Bertrand, Marianne, Esther Duflo, and Sendhil Mullainathan. 2004. "How Much Should We Trust Differences-in-Differences Estimates?", Quarterly Journal of Economics 119, 249-275

[4] Blonigen, Bruce A., Ronald B. Davies, Glen R. Waddell and Helen Naughton. 2007. "FDI in Space: Spatial Autoregressive Relationships in Foreign Direct Investment", European Economic Review 51, 1303-1325

[5] Chung, Sunghoon. 2014. "Environmental Regulation and Foreign Direct Investment: Evidence from South Korea", Journal of Development Economics 108, 222-236

[6] Dean, Judith M. and Mary E. Lovely. 2010. "Trade Growth, Production Fragmentation, and China's Environment", in Robert Feenstra and Shang-jin Wei ed., China's Growing Role in World Trade, Chicago: NBER and University of Chicago Press

[7] Dean, Judith M., Mary E. Lovely, and Hua Wang. 2009. "Are Foreign Investors Attracted to Weak Environmental Regulations? Evaluating the Evidence from China", Journal of Development Economics 90, 1-13

[8] Drukker, David and Daniel L. Millimet. 2008. "Assessing the Pollution Haven Hypothesis in an Interdependent World", working paper

[9] Eskeland, Gunnar S. and Ann E. Harrison. 2003. "Moving to Greener Pastures? Multinationals and the Pollution Haven Hypothesis", Journal of Development Economics 70, 1-23

[10] Friedman, Joseph, Daniel A. Gerlowski, and Johnathan Silberman. 1992. "What Attracts Foreign Multinational Corporations? Evidence from Branch Plant Location in the United States", Journal of Regional Science 32, 403-418

[11] Gentzkow, Matthew. 2006. "Television and Voter Turnout", Quarterly Journal of Economics 121, 931-972

[12] Hanna, Rema. 2011. "US Environmental Regulation and FDI: Evidence from a Panel of US-Based Multinational Firms", American Economic Journal: Applied Economics $2,158-189$ 
[13] Hao, Jiming, Shuxiao Wang, Bingjiang Liu, and Kebin He. 2001. "Plotting of Acid Rain and Sulfur Dioxide Pollution Control Zones and Integrated Control Planning in China", Water, Air, and Soil Pollution 230, 259-264

[14] He, Kebin, Hong Huo, and Qiang Zhang. 2002. "Urban Air Pollution in China: Current Status, Characteristics, and Progress", Annual Review of Energy and the Environment 27, 397-431

[15] Henderson, Vernon. 1996. "Effects of Air Quality Regulation", American Economic Review 86, 789-813

[16] Hering, Laura and Sandra Poncet. 2014. "Environmental Policy and Trade Performance: Evidence from China", Journal of Environmental Environmental Economics and Management 68, 296-318

[17] Javorcik, Beata S. and Shang-jin Wei. 2004. "Pollution Havens and Foreign Direct Investment: Dirty Secret or Popular Myth?", Contributions to Economic Analysis \& Policy 3, Article 8

[18] Jeppesen, Tim, John A. List, and Henk Folmer. 2002. "Environmental Regulations and New Plant Location Decisions: Evidence from a Meta-Analysis", Journal of Regional Science 42, 19-49

[19] Kellenberg, Derek K. 2009. "An Empirical Investigation of the Pollution Haven Effect with Strategic Environment and Trade Policy", Journal of International Economics 78, 242-255

[20] Keller, Wolfgang and Arik Levinson. 2002. "Pollution Abatement Costs and Foreign Direct Investment Inflows to U.S. States", Review of Economics and Statistics 84, 691-703

[21] Levinson, Arik. 1996. "Environmental Regulations and Manufacturer's Location Choices: Evidence from the Census of Manufactures", Journal of Public Economics $62,5-29$

[22] Levinson, Arik. 2008. "Pollution Haven Hypothesis", New Palgrave Dictionary of Economics, 2nd edition

[23] List, John A. 1999. "Have Air Pollutant Emissions Converged among U.S. Regions? Evidence from Unit Root Tests", Southern Economic Journal 66, 144-155

[24] List, John A. and Catherine Y. Co. 2000. "The Effects of Environmental Regulations on Foreign Direct Investment", Journal of Environmental Economics and Management 40, 1-20 
[25] List, John A., W. Warren McHone, and Daniel L. Millimet. 2004. "Effects of Environmental Regulation on Foreign and Domestic Plant Births: Is There a Home Field Advantage?", Journal of Urban Economics 56, 303-26

[26] List, John A., Daniel L. Millimet, Per G. Fredriksson, and W. Warren McHone. 2003. "Effects of Environmental Regulations on Manufacturing Plant Births: Evidence from A Propensity Score Matching Estimator", Review of Economics and Statistics 85, 944-952

[27] Millimet, Daniel L. and John A. List. 2004. "The Case of the Missing Pollution Haven Hypothesis", Journal of Regulatory Economics 26, 239-262

[28] Millimet, Daniel L. and Joyjit Roy. 2011. "Three New Empirical Tests of the Pollution Haven Hypothesis When Environmental Regulation is Endogenous", working paper

[29] Staiger, Douglas and James H. Stock. 1997. "Instrumental Variables Regression with Weak Instruments", Econometrics 65, 557-586

[30] Stock, James H. and Mark W. Watson. 2012. Introduction to Econometrics, 3rd Edition, Essex, England: Pearson Education Limited

[31] Wagner, Ulrich J. and Christopher Timmins. 2009. "Agglomeration Effects in Foreign Direct Investment and the Pollution Haven Hypothesis", Environmental and Resource Economics 43, 231-256

[32] Yang, Jintian, Dong Cao, Chazhong Ge, and Shuting Gao. 2002. "Air Pollution Control Strategy for China's Power Sector", Chinese Academy for Environmental Planning, Beijing, China 


\section{Appendix: Designation of TCZ Cities}

A key challenge of using the TCZ policy as a quasi-natural experiment to investigate the effect of environmental regulation of FDI is that the designation of TCZ cities may be correlated with some unobserved determinants of FDI. Note that we employ city fixed effect in all the following regressions; hence, the relevant concern is whether the designation of TCZ cities is correlated with any pre-existing city trends, in particular, the time trend for FDI. Two facts presented in section 2 may help relieve such a concern. First, the initiation of the TCZ policy and the designation of TCZ status were conducted by the central government and were largely exogenous to lower-level (such as city) governments. Second, the designation of TCZ cities was based on several criteria, in particular past pollution levels (i.e., ambient $\mathrm{SO} 2$ concentration value or $\mathrm{pH}$ value of precipitation) and specific threshold levels, neither of which could be manipulated by city governments retrospectively.

Nonetheless, we conduct a quantitative analysis for a better understanding of the determinants of TCZ designation. Specifically, we look at geographical factors (i.e., whether the city is in the north, by the coastal, or in the mountains), political factors (i.e., whether the city is a municipality or a provincial capital city, in a special economic zone, or an old industrial city), economic factors (i.e., economic development, industrial production, number of firms, proportion of polluting industries, population), as well as the amount of FDI and past pollution levels. See Table 1 for the details of the construction and summary statistics of these variables.

The Probit regression results are reported in Appendix Table A3. We start with the investigation of geographic factors in column 1. It is found that cities located in northern and coastal areas are less likely to be designated as TCZ cities, while those located in mountainous areas are more likely to be (albeit statistically insignificant). These are consistent with our expectation, as inland cities are more likely to retain SO2 concentrations over long periods of time because they are not reached by prevailing winds, and it may take a longer time for SO2 emission to disperse in cities surrounded by mountains. Meanwhile, northern cities are less likely to be designated as TCZ cities because of their heating systems and their heavy reliance on thermal instead of hydro powers due to lack of rainfall. In column 2, we add political factors. While municipalities, provincial capital cities and old industrial cities are found to be more likely to become TCZ cities initially, the coefficients become highly insignificant once economic factors are added. Cities in special economic zones are consistently found to be more likely to be designated as TCZ cities, suggesting that these special economic zones may be at the top of the government agenda.

We go on to include economic factors in column 3, and find that cities with larger industrial production and a larger proportion of polluting industries are more likely to 
become TCZ cities. These results are consistent with casual observations that the fast economic growth in recent decades in China has been accomplished with severe damage to the environment.

In column 4, we investigate whether conditional on these important potential determinants, the designation of TCZ was caused by the past FDI, or whether there is a concern about reverse causality. It is clear that the estimated coefficient of FDI is not only statistically insignificant, but is also very small in magnitude, implying that the concern about reverse causality is not relevant in our research setting.

In summary, our quantitative analysis shows that the location of the city, its industrial production, and the proportion of polluting industries are important and significant factors in determining whether a city was designated as a TCZ city. Meanwhile, conditional on these determinants, we do not find evidence of the TCZ status being determined by past FDI. 
Figure 1: Geographic distribution of TCZ cities

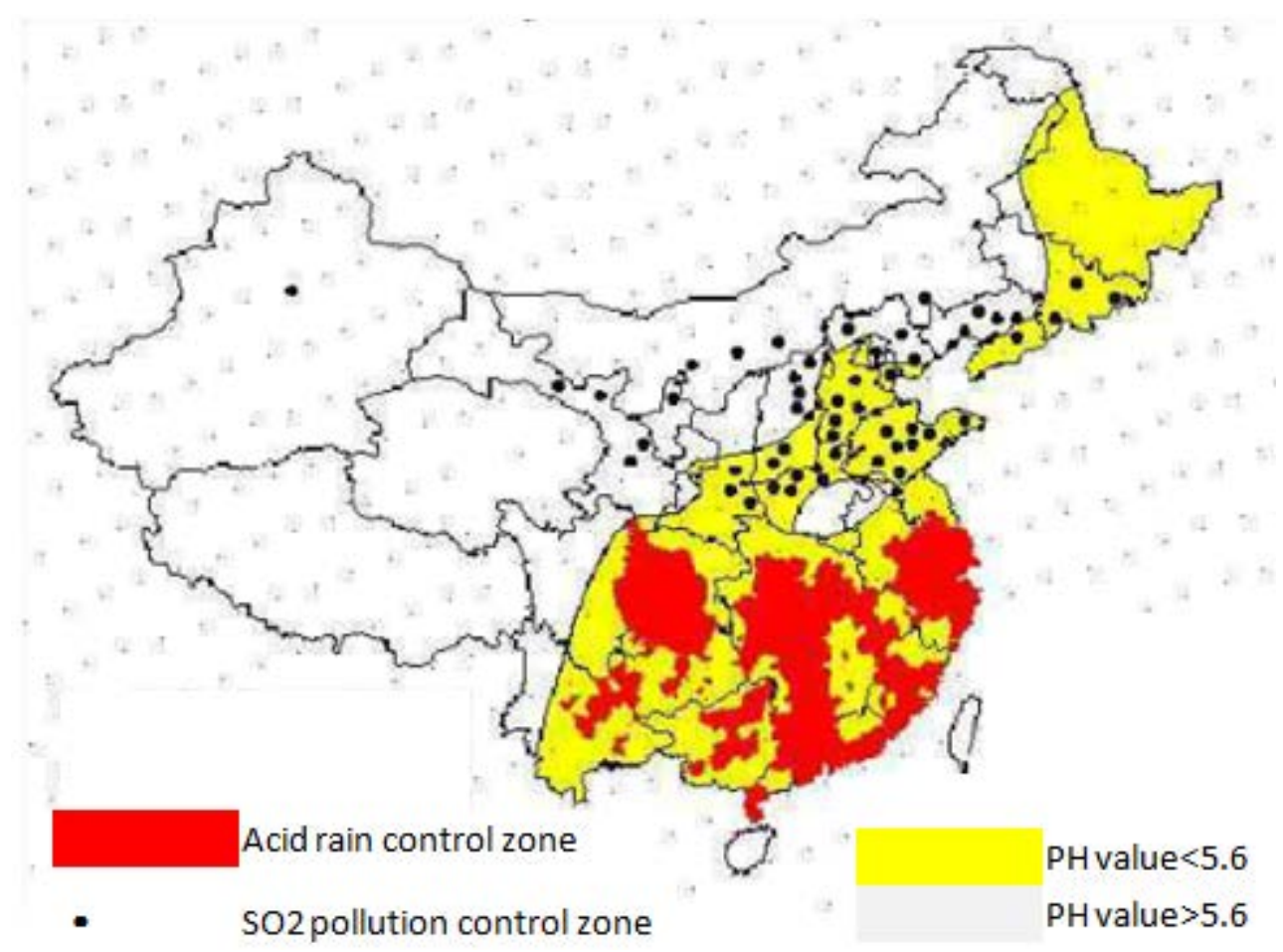

(Source: The national Environmental Protection Bureau, “The Proposal of Designation for Acid Rain Control Areas and SO2 Pollution Control Areas") 
Figure 2: Time trends of FDI inflows in TCZ and non-TCZ cities, and their difference
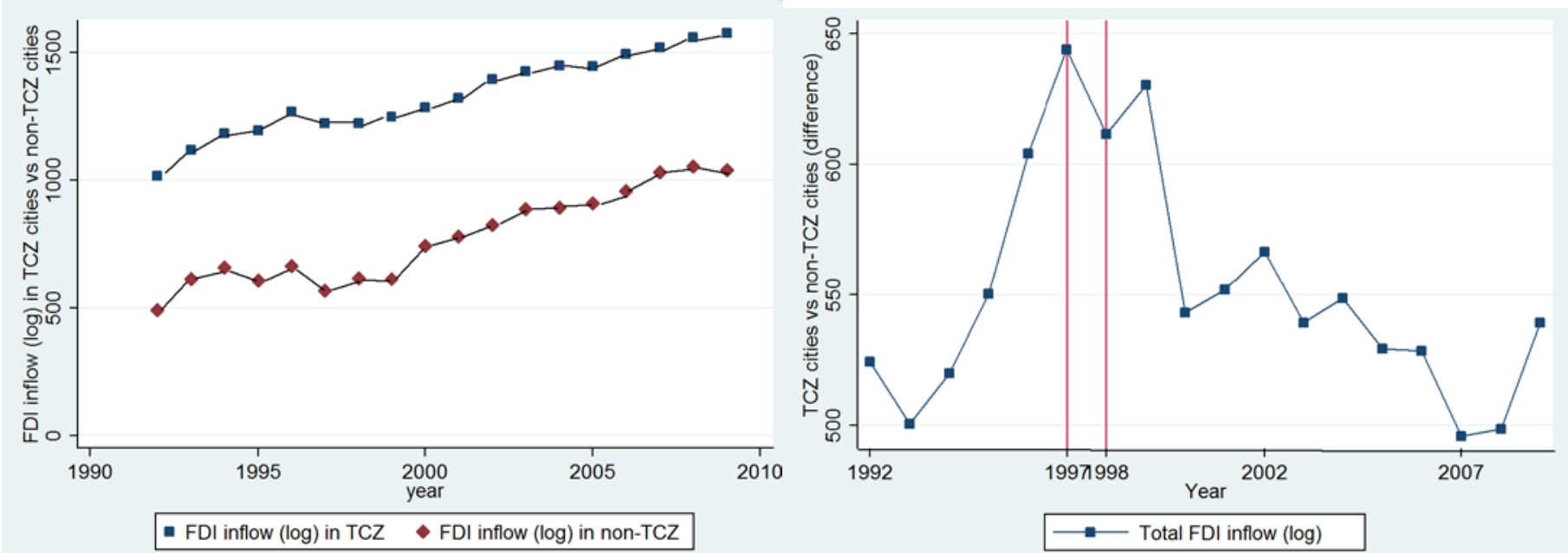
Figure 3: Kernel density of 500 estimates

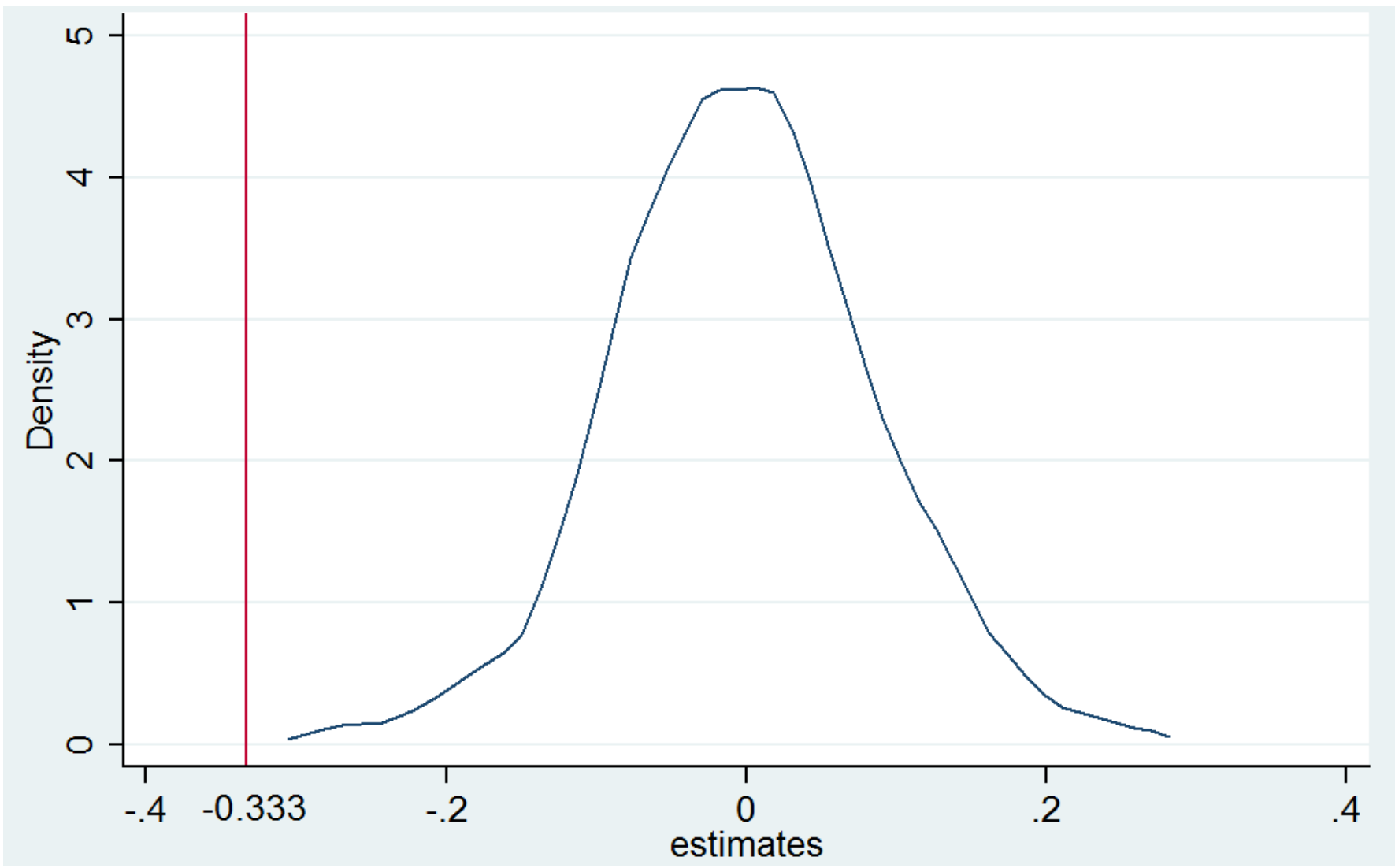


Table 1: Summary statistics and description of variables

\begin{tabular}{|c|c|c|c|c|c|c|}
\hline Variable name & Obs. & Mean & S.D. & Min & Max & Description \\
\hline$\overline{T C Z}$ & 5166 & 0.56 & 0.50 & 0 & 1 & Dummy variable taking value of 1 if the city is designated as TCZ, 0 otherwise \\
\hline Post & 5166 & 0.67 & 0.47 & 0 & 1 & Dummy variable taking value of 1 if year is 1998 or afterwards, 0 otherwise \\
\hline FDI (log) & 4485 & 8.45 & 2.06 & 0.69 & 13.87 & Amount of real FDI received $(10,000$ USD) \\
\hline Domestic output (log) & 4764 & 14.68 & 1.46 & 9.81 & 19.34 & Output of the industrial sector $(10,000 \mathrm{CNY})$ \\
\hline Retail consumption (log) & 4566 & 13.65 & 1.23 & 8.99 & 17.79 & Total retail sales of social consumption goods $(10,000 \mathrm{CNY})$ \\
\hline Tax revenue (log) & 3997 & 11.54 & 1.33 & 7.05 & 15.75 & Fiscal revenue and tax collected by government \\
\hline GDP per capita (log) & 4256 & 9.15 & 0.83 & 6.85 & 12.74 & Per capita GDP \\
\hline College students (log) & 4143 & 9.37 & 1.53 & 3.22 & 13.65 & Number of college students \\
\hline Telephones (log) & 4009 & 3.78 & 1.11 & -0.35 & 7.46 & Number of telephones owned by every 10,000 households \\
\hline Total road area (log) & 4150 & 6.03 & 1.03 & 0.00 & 9.98 & Total paved road area (square meters) \\
\hline High school students (log) & 4606 & 12.04 & 0.90 & 4.61 & 14.65 & Number of high school students $(10,000)$ \\
\hline Electricity consumption & 4734 & 11.97 & 1.26 & 7.72 & 16.26 & Total Electricity consumption (10,000 kW.h) \\
\hline Historical FDI stock & 4750 & 9.95 & 2.31 & 0.69 & 16.11 & Historical FDI stock since 1992 (10,000 USD) \\
\hline Spatially lagged FDI & 4526 & 13.48 & 0.60 & 11.82 & 14.79 & inverse-distance-weighted average of the FDI in all other cities (10.000 USD) \\
\hline Wholly-owned FDI presence & 5130 & 0.14 & 0.18 & 0.00 & 0.91 & Percentage of wholly-owned FDI in total FDI inflow \\
\hline Trade exposure & 4644 & 0.05 & 0.17 & 0.00 & 0.85 & Ratio of Trade value (import and export) in GDP \\
\hline SOEs presence & 4644 & 0.21 & 0.08 & 0.04 & 0.55 & Share of SOEs in all firms (in number) \\
\hline Northern & 5148 & 0.48 & 0.50 & 0 & 1 & Northern cities of China \\
\hline Coastal & 5166 & 0.15 & 0.36 & 0 & 1 & Coastal cities of China \\
\hline Mountains & 5166 & 0.34 & 0.48 & 0 & 1 & City surrounded by mountains \\
\hline Municipality & 5166 & 0.01 & 0.12 & 0 & 1 & Four municipalities of China (Beijing, Shanghai, Tianjin, Chongqing) \\
\hline Provincial capital city & 5166 & 0.09 & 0.29 & 0 & 1 & Provincial capital cities in China (27 cities) \\
\hline Old industrial cities & 5166 & 0.12 & 0.32 & 0 & 1 & City with large number of old plants (former industry basis) \\
\hline Total employment (log) & 4266 & 3.35 & 0.78 & 0.31 & 6.32 & Total number of employed persons $(10,000)$ \\
\hline Number of firms (log) & 3304 & 6.22 & 1.14 & 2.94 & 9.84 & Total number of industrial firms \\
\hline Share of air-polluted industries & 4914 & 0.27 & 0.16 & 0.01 & 0.94 & Output share of air polluted industries in total output of the city \\
\hline
\end{tabular}


Table 2: Main results

\begin{tabular}{lcccc}
\hline \hline & $(1)$ & $(2)$ & $(3)$ & $(4)$ \\
\cline { 2 - 5 } DV: log FDI & & & Neighboring cities \\
\hline TCZ * Post & $-0.318^{* *}$ & $-0.276^{* *}$ & $-0.333^{* *}$ & $-0.314^{* * *}$ \\
& $(0.122)$ & $(0.118)$ & $(0.139)$ & $(0.102)$
\end{tabular}

Time-varying controls

City fixed effects

Year fixed effects

Province-year fixed effects

Interactions between Post and:

Northern areas

Coastal areas

Municipality or provincial capital city

Special economic zones

Old industrial cities

Industrial production (92-97)

Share of polluted industries (95)

Observations

\begin{tabular}{|c|c|c|c|}
\hline$X$ & $X$ & $X$ & $x$ \\
\hline$X$ & $X$ & $X$ & $X$ \\
\hline \multicolumn{4}{|l|}{$X$} \\
\hline & $X$ & $X$ & $X$ \\
\hline & & $X$ & $X$ \\
\hline & & $X$ & $X$ \\
\hline & & $X$ & $X$ \\
\hline & & $x$ & $x$ \\
\hline & & $X$ & $x$ \\
\hline & & $X$ & $x$ \\
\hline & & $X$ & $X$ \\
\hline ,367 & 3,367 & 3,117 & 4,236 \\
\hline .448 & 0.623 & 0.636 & 0.713 \\
\hline
\end{tabular}

R-squared

0.448

0.623

$x$

$X$

Note: Standard errors, clustered at the city level, are reported in the parenthesis. * ${ }^{\star \star}$ and ${ }^{* \star *}$ represent

statistical significance at the $10 \%, 5 \%$ and $1 \%$ level, respectively. 
Table 3, Checks on the identifying assumption

\begin{tabular}{|c|c|c|c|c|c|c|c|}
\hline & $(1)$ & $(2)$ & (3) & $(4)$ & $(5)$ & $(6)$ & $(7)$ \\
\hline DV: log FDI & $\begin{array}{c}\text { Incl. } \\
\text { City-time } \\
\text { trend }\end{array}$ & $\begin{array}{c}\text { Incl. } \\
\text { Pre-existing } \\
\end{array}$ & $\begin{array}{l}\text { Use } 1996 \text { as } \\
\text { event date }\end{array}$ & $\begin{array}{c}\text { Incl. } \\
\text { Trade } \\
\text { exposure }\end{array}$ & $\begin{array}{c}\text { Incl. } \\
\text { SOEs } \\
\text { presence }\end{array}$ & $\begin{array}{l}\text { Incl. wholly- } \\
\text { owned FDI }\end{array}$ & $\begin{array}{c}\text { Fake } \\
\text { treatment } \\
\text { group }\end{array}$ \\
\hline TCZ * Post & $\begin{array}{l}-0.416 * \star \\
(0.209)\end{array}$ & $\begin{array}{l}-0.346 * * \\
(0.156)\end{array}$ & $\begin{array}{l}-0.243 \\
(0.151)\end{array}$ & $\begin{array}{l}-0.331^{\star *} \\
(0.139)\end{array}$ & $\begin{array}{l}-0.330 \star \star \\
(0.139)\end{array}$ & $\begin{array}{l}-0.329 * * \\
(0.140)\end{array}$ & $\begin{array}{c}0.223 \\
(0.153)\end{array}$ \\
\hline TCZ * Next year & & $\begin{array}{l}-0.048 \\
(0.198)\end{array}$ & & & & & \\
\hline Trade exposure * Post & & & & $\begin{array}{c}0.159 \\
(0.256)\end{array}$ & & & \\
\hline SOEs presence * Post & & & & & $\begin{array}{c}0.118 \\
(0.945)\end{array}$ & & \\
\hline Full-owned FDI presence * Post & & & & & & $\begin{array}{c}0.117 \\
(0.355)\end{array}$ & \\
\hline Time-varying controls & $X$ & $x$ & $x$ & $x$ & $x$ & $x$ & $x$ \\
\hline City fixed effects & $x$ & $x$ & $x$ & $X$ & $X$ & $X$ &  \\
\hline $\begin{array}{l}\text { Province-Year effects } \\
\text { Interactions between Post and }\end{array}$ & $x$ & $x$ & $x$ & $x$ & $x$ & $x$ & $x$ \\
\hline determinants of $\mathrm{TCZ}$ designation & $x$ & $x$ & $x$ & $x$ & $x$ & $x$ & $x$ \\
\hline Observations & 2,741 & 3,117 & 3,117 & 3,096 & 3,096 & 3,097 & 3,117 \\
\hline R-squared & 0.044 & 0.636 & 0.634 & 0.635 & 0.635 & 0.642 & 0.635 \\
\hline
\end{tabular}

Note: Standard errors, clustered at the city level, are reported in the parenthesis. ${ }^{*},{ }^{\star *}$ and ${ }^{* \star \star}$ represent statistical significance at $10 \%, 5 \%$ and $1 \%$ level, respectively. 
Table 4, Heterogeneous effects across industries and triple-difference estimation

\begin{tabular}{|c|c|c|c|}
\hline DV: $\log F D I$ & $\begin{array}{c}\text { (1) } \\
\text { Polluting } \\
\text { industries }\end{array}$ & $\begin{array}{c}\text { (2) } \\
\text { Non-polluting } \\
\text { industries }\end{array}$ & $\begin{array}{c}(3) \\
\text { Triple difference }\end{array}$ \\
\hline TCZ * Post & $\begin{array}{l}-0.773^{\star} \\
(0.393)\end{array}$ & $\begin{array}{c}0.016 \\
(0.224)\end{array}$ & \\
\hline TCZ * Post * Polluting & & & $\begin{array}{c}-0.322^{\star *} \\
(0.161)\end{array}$ \\
\hline Time-varying controls & $x$ & $x$ & \\
\hline City fixed effects & $x$ & $x$ & \\
\hline Province-Year effects & $x$ & $x$ & \\
\hline Interactions between Post and determinants of TCZ designation & $x$ & $x$ & \\
\hline City-year fixed effects & & & $x$ \\
\hline City-industry fixed effects & & & $x$ \\
\hline Industry-year fixed effects & & & $x$ \\
\hline Observations & 1,290 & 1,290 & 5,740 \\
\hline R-squared & 0.694 & 0.909 & 0.925 \\
\hline
\end{tabular}


Appendix Table 1: TCZ cities and their neighboring non-TCZ cities in China

\begin{tabular}{|c|c|c|c|c|c|}
\hline Province & TCZ city & Neighboring non-TCZ cities & Province & TCZ city & Neighboring Non-TCZ cities \\
\hline Beijing & & Langfang & & Zhenjiang & Huaian \\
\hline Tianjin & & Langfang Cangzhou & & Taizhou & Yancheng \\
\hline \multirow[t]{8}{*}{ Hebei } & Shijiangzhuang & Jinzhong & Zhejiang & Hangzhou & Lishui Shangrao \\
\hline & Tangshan & Qinhuangdao & & Ningbo & Zhoushan \\
\hline & Handan & Liaocheng Changzhi Puyang & & Wenzhou & Lishui Ningde \\
\hline & Xingtai & Liaocheng Jinzhong & & Jiaxing & Zhoushan Lishui \\
\hline & Baoding & Langfang Cangzhou & & Huzhou & Zhoushan Chizhou \\
\hline & Zhangjiakou & Wulancabu & & Shaoxing & Lishui \\
\hline & Chengde & Caoyang Qinhuangdao & & Jinhua & Lishui \\
\hline & Hengshui & Cangzhou & & Quzhou & Lishui Shangrao \\
\hline \multirow[t]{7}{*}{ Shanxi } & Taiyuan & Luliang Jinzhong & & Taizhou & Lishui \\
\hline & Datong & Wulancabu & Anhui & Wuhu & Chizhou \\
\hline & Yangquan & Jinzhong & & Manshan & Chuzhou \\
\hline & Shuozhou & Wulanchabu & & Tongling & Anqing Chizhou \\
\hline & Yuncheng & Jincheng & & Huangshan & Chizhou Jingdezhen Shangrao \\
\hline & Xinzhou & Luliang & & Xuancheng & Chizhou \\
\hline & Linfen & Jincheng Changzhi & Fujian & Fuzhou & Ningde Putian Nanping \\
\hline \multirow[t]{4}{*}{ Inner Mongolia } & Huhehaote & Wulancabu Eerduosi & & Xiamen & Putian \\
\hline & Baotou & Bayanzuoer Eerduosi & & Sanming & Nanping \\
\hline & Wuhai & Eerduosi & & Quanzhou & Putian \\
\hline & Chifeng & Chaoyang Tongliao & & Zhangzhou & Meizhou \\
\hline \multirow[t]{9}{*}{ Liaoning } & Shenyang & Tieling & & Longyan & Meizhou \\
\hline & Dalian & Yingkou Dandong & Jiangxi & Nanchang & Shangrao Yichun Fuzhou \\
\hline & Anshan & Panjin Yingkou Dandong & & Pingxiang & Yichun \\
\hline & Fushun & Tieling & & Jiujiang & Huanggang Anqing Yichun Shangrao \\
\hline & Benxi & Dandong & & Yingtan & Shangrao Nanping Fuzhou \\
\hline & Jinzhou & Panjin Chaoyang & & Ganzhou & Heyuan \\
\hline & Fuxin & Tongliao Chaoyang & & Ji'an & XinYu Yichun \\
\hline & Liaoyang & Dandong & Shandong & Jinan & Liaocheng Binzhou \\
\hline & Huludao & Qinhuangdao Chaoyang & & Qingdao & Rizhao \\
\hline \multirow[t]{3}{*}{ Jinlin } & Jilin & Changchun Baishan & & Zibo & Dongying Binzhou Linyi \\
\hline & Siping & Changchun Tieling Songyuan Tongliao & & Zaozhuang & Linyi \\
\hline & Tonghua & Baishan & & Yantai & Weihai \\
\hline Shanghai & & Yancheng & & Weifang & Rizhao Dongying \\
\hline \multirow[t]{8}{*}{ Jiangsu } & Nanjing & Huaian Yancheng & & Jining & Linyi Heze Puyang \\
\hline & Wuxi & Huaian Yancheng & & Taian & Linyi \\
\hline & Xuzhou & Linyi Lianyungang Suqian Suzhou Huaibei & & Laiwu & Linyi \\
\hline & Changzhou & Chuzhou & & Dezhou & Liaocheng Cangzhou Binzhou \\
\hline & Suzhou & Huaian Yancheng & Henan & Zhengzhou & Kaifeng Xinxiang Xuchang \\
\hline & Nantong & Yancheng & & Luoyang & Jincheng Nanyang Pingdingshan \\
\hline & Yangzhou & Huaian Yancheng Chuzhou & & Anyang & Changzhi Xinxiang Hebi Puyang \\
\hline & & & & Jiaozuo & Xinxiang Jincheng \\
\hline
\end{tabular}




\begin{tabular}{|c|c|c|}
\hline \multirow[t]{2}{*}{ Province } & TCZ city & Neighboring Non-TCZ cities \\
\hline & Sanmenxia & Nanyang \\
\hline \multirow[t]{7}{*}{ Hubei } & Wuhan & Huanggang Xiaogan \\
\hline & Huangshi & Huanggang \\
\hline & Yichang & Xiangfan \\
\hline & Ezhou & Huanggang \\
\hline & Jingmeng & Xiangfan Xiaogan Suizhou \\
\hline & Jingzhou & Xiaogan \\
\hline & Xianning & Huanggang \\
\hline \multirow[t]{11}{*}{ Hunan } & Changsha & Yichun \\
\hline & Zhuzhou & Yichun \\
\hline & Xiangtan & Yichun \\
\hline & Hengyang & Shaoyang Yongzhou \\
\hline & Yueyang & Yichun \\
\hline & Changde & Shaoyang \\
\hline & Zhangjiajie & Shaoyang \\
\hline & Yiyang & Shaoyang \\
\hline & Chenzhou & Yongzhou \\
\hline & Huaihua & Shaoyang \\
\hline & Loudi & Shaoyang \\
\hline \multirow[t]{17}{*}{ Guangdong } & Guangzhou & Heyuan \\
\hline & Shaoguan & Heyuan \\
\hline & Shenzhen & Heyuan \\
\hline & Zhuhai & Yangjiang \\
\hline & Shantou & Meizhou \\
\hline & Foshan & Yangjiang \\
\hline & Jiangmen & Yangjiang \\
\hline & Zhanjiang & Maoming Beihai \\
\hline & Zhaoqing & Yongzhou \\
\hline & Huizhou & Heyuan \\
\hline & Shanwei & Heyuan Meizhou \\
\hline & Qingyuan & Yongzhou \\
\hline & Dongguan & Heyuan \\
\hline & Zhongshan & Yangjiang \\
\hline & Chaozhou & Meizhou \\
\hline & Jieyang & Meizhou \\
\hline & Yunfu & Yangjiang Maoming \\
\hline \multirow[t]{5}{*}{ Guangxi } & Nanning & Laibin Qinzhou Chongzuo \\
\hline & Liuzhou & Laibin \\
\hline & Guilin & Yongzhou \\
\hline & Wuzhou & Laibin Guigang \\
\hline & Guigang & Laibin \\
\hline
\end{tabular}

\begin{tabular}{|c|c|c|}
\hline \multirow[t]{4}{*}{ Province } & TCZ city & Neighboring Non-TCZ cities \\
\hline & Yulin & Maoming Beihai Qinzhou Guigang \\
\hline & Hezhou & Yongzhou \\
\hline & Hechi & Baise Laibin \\
\hline Chongqing & & Dazhou Guangan Ziyang \\
\hline \multirow[t]{13}{*}{ Sichuan } & Chengdu & Yaan Ziyang \\
\hline & Zigong & Laibin \\
\hline & Panzhihua & Lijiang \\
\hline & Luzhou & Ziyang \\
\hline & Deyang & Ziyang \\
\hline & Mianyang & Guangyuan Longlan \\
\hline & Suining & Ziyang \\
\hline & Neijiang & Ziyang \\
\hline & Leshan & Yaan \\
\hline & Nanchong & Guangyuan Bazhong Dazhou \\
\hline & Yibin & Yaan Ziyang \\
\hline & Guangan & Dazhou \\
\hline & Meishan & Yaan Ziyang \\
\hline \multirow[t]{3}{*}{ Guizhou } & Guiyang & Liupanshui \\
\hline & Zunyi & Liupanshui \\
\hline & Anshun & Liupanshui \\
\hline \multirow[t]{4}{*}{ Yunnan } & Kunming & Simao Lincang \\
\hline & Qujing & Liupanshui \\
\hline & Yuxi & Simao Lincang \\
\hline & Zhaotong & Lijiang Liupanshui \\
\hline \multirow[t]{4}{*}{ Shaanxi } & Xian & Xianyang Baoji Ankang \\
\hline & Tongchuan & Yanan Xianyang \\
\hline & Weinan & Yanan Xianyang \\
\hline & Shangluo & Ankang \\
\hline \multirow[t]{4}{*}{ Gansu } & Lanzhou & Dingxi Wuwei \\
\hline & Jinchang & Wuwei \\
\hline & Baiyin & Wuwei Dingxi Guyuan Pingliang Zhongwei \\
\hline & Zhangye & Jiuquan \\
\hline \multirow[t]{2}{*}{ Ningxia } & Yinchuan & Wuzhong \\
\hline & Shizuishan & Eerduosi \\
\hline Xinjiang & Wulumuqi & Kelamayi \\
\hline
\end{tabular}


Appendix Table A2: Other robustness checks

\begin{tabular}{|c|c|c|c|}
\hline & $(1)$ & $(2)$ & $(3)$ \\
\hline Dep. Var. (log FDI) & Historical FDI stock & Excl. Municipalities & Spatially lagged FDI \\
\hline TCZ * Post & $\begin{array}{c}-0.305^{\star \star} \\
(0.142)\end{array}$ & $\begin{array}{c}-0.329 * \star \\
(0.139)\end{array}$ & $\begin{array}{c}-0.345^{\star *} \\
(0.138)\end{array}$ \\
\hline Historical FDI stock (log) & $\begin{array}{l}0.963^{* * *} \\
(0.073)\end{array}$ & & \\
\hline Spatially lagged FDI (log) & & & $\begin{array}{l}-2.334 \\
(1.837)\end{array}$ \\
\hline Time-varying controls & $x$ & $x$ & $x$ \\
\hline City fixed effects & $x$ & $x$ & $x$ \\
\hline Province-Year effects & $x$ & $x$ & $x$ \\
\hline $\begin{array}{l}\text { Interactions between Post and } \\
\text { determinants of TCZ designation }\end{array}$ & $x$ & $x$ & $x$ \\
\hline Observations & 3,117 & 3,074 & 3,117 \\
\hline R-squared & 0.700 & 0.634 & 0.639 \\
\hline
\end{tabular}


Appendix Table A3: Determinants of TCZ designation

\begin{tabular}{|c|c|c|c|c|}
\hline DV: dummy variable of designating as TCZ & (1) & (2) & (3) & (4) \\
\hline Northern & $\begin{array}{c}-0.235^{\star \star \star} \\
(0.074)\end{array}$ & $\begin{array}{c}-0.305^{\star \star \star} \\
(0.092)\end{array}$ & $\begin{array}{c}-0.276^{\star \star \star} \\
(0.091)\end{array}$ & $\begin{array}{c}-0.282^{\star \star \star} \\
(0.102)\end{array}$ \\
\hline Coastal & $\begin{array}{l}-0.026 \\
(0.077)\end{array}$ & $\begin{array}{c}-0.206^{\star \star} \\
(0.079)\end{array}$ & $\begin{array}{c}-0.267^{\star \star \star} \\
(0.085)\end{array}$ & $\begin{array}{c}-0.249^{\star \star} \\
(0.094)\end{array}$ \\
\hline Mountainous & $\begin{array}{c}0.095 \\
(0.064)\end{array}$ & $\begin{array}{c}0.089 \\
(0.064)\end{array}$ & $\begin{array}{c}0.112 \\
(0.066)\end{array}$ & $\begin{array}{l}0.171^{\star *} \\
(0.073)\end{array}$ \\
\hline Municipality or provincial capital city & & $\begin{array}{l}0.182^{\star \star} \\
(0.084)\end{array}$ & $\begin{array}{c}0.012 \\
(0.078)\end{array}$ & $\begin{array}{c}0.008 \\
(0.081)\end{array}$ \\
\hline Special economic zones & & $\begin{array}{l}0.345^{\star \star} \\
(0.127)\end{array}$ & $\begin{array}{l}0.200^{\star} \\
(0.100)\end{array}$ & $\begin{array}{l}0.204^{*} \\
(0.109)\end{array}$ \\
\hline Old industrial cities & & $\begin{array}{l}0.273^{\star *} \\
(0.119)\end{array}$ & $\begin{array}{c}0.079 \\
(0.096)\end{array}$ & $\begin{array}{c}0.065 \\
(0.116)\end{array}$ \\
\hline GDP per capita (92-97) & & & $\begin{array}{c}0.000 \\
(0.000)\end{array}$ & $\begin{array}{c}0.000 \\
(0.000)\end{array}$ \\
\hline Industrial production (92-97) & & & $\begin{array}{l}0.181^{\star} \\
(0.104)\end{array}$ & $\begin{array}{c}0.204 \\
(0.130)\end{array}$ \\
\hline Number of firms (92-97) & & & $\begin{array}{c}0.032 \\
(0.062)\end{array}$ & $\begin{array}{c}0.022 \\
(0.059)\end{array}$ \\
\hline Tax revenue (92-97) & & & $\begin{array}{c}0.007 \\
(0.085)\end{array}$ & $\begin{array}{c}0.007 \\
(0.103)\end{array}$ \\
\hline Output share of SO2-polluting industries (95) & & & $\begin{array}{c}0.711^{\star * *} \\
(0.209)\end{array}$ & $\begin{array}{c}0.823^{\star * *} \\
(0.291)\end{array}$ \\
\hline Population (92-97) & & & $\begin{array}{l}-0.070 \\
(0.066)\end{array}$ & $\begin{array}{l}-0.095 \\
(0.086)\end{array}$ \\
\hline FDI (92-97) & & & & $\begin{array}{c}0.003 \\
(0.004)\end{array}$ \\
\hline SO2 (95) & & & & \\
\hline I [SO2>=60ug/m3] & & & & \\
\hline Observations & 286 & 286 & 244 & 230 \\
\hline R-squared & 0.068 & 0.131 & 0.342 & 0.387 \\
\hline
\end{tabular}

